\title{
A IMPLEMENTAÇÃO DA COMISSÃO NACIONAL DO LIVRO DIDÁTICO NO ESTADO NOVO (1937-1945)
}

\section{IMPLEMENTATION OF NATIONAL COMMISSION OF TEXTBOOK IN THE "ESTADO NOVO" (1937-1945)}

Alesson Ramon Rotal

Resumo: O presente artigo tem o objetivo de discutir as contribuições da Comissão Nacional dos Livros Didático (CNLD) para a política governamental do Estado Novo (1937-1945). Durante os anos da ditadura houveram algumas implementações educacionais. Uma delas é a criação da CNLD, órgão que objetivou regular e fiscalizar todos os livros didáticos em circulação no país. Para verificarmos a repercussão da CNLD no interior do livro didático utilizamos um livro de história de uso oficial do Estado. Nele constatamos que a escrita da história da época pautada em uma teoria historicista, também contribuiu para propagandear uma imagem positiva do Governo Vargas.

Palavras-Chave: Livros Didáticos, Estado Novo, Comissão Nacional do Livro didático.

Abstract: This article aims to discuss the contributions of the Comissão Nacional do Livro Didático (CNLD) for government policy of the Estado Novo (1937-1945). During the years of the dictatorship there were some educational implementations. One is the creation of CNLD, a body that aims to regulate and supervise all textbooks in circulation. To check the impact of CNLD inside the textbook we use a history book of official use of the State. In it we find that the writing of the history of

\footnotetext{
${ }^{1}$ Graduando do quinto semestre do curso de História da Universidade Federal do Rio Grande, com pesquisas nas áreas da História do Ensino de História e Historiografia. Lattes: http://lattes.cnpq.br/3896360099405972. Trabalho orientado pela Dr ${ }^{\mathrm{a}}$. Júlia Silveira Matos.
} 
that time ruled in a historicist theory, also contributed to advertise a positive image of the Government Vargas.

Keywords: Textbook, New State, National Committee on Textbook

\section{Introdução}

O Estado Novo brasileiro foi uma forma de política inaugurada em 1937 pelo presidente Getúlio Vargas. Na época haviam extremismos tanto da direita representada pela Ação Integralista Brasileira, quanto da esquerda representada pela Aliança Nacional Libertadora, que se embasou nas ideias Comunistas. Em 1937, Vargas, o então eleito constitucionalmente presidente do país se aproveita do extremismo desses grupos para dar um golpe de Estado e criar uma ditadura.

O Estado Novo brasileiro faz parte de um conjunto de políticas ditatoriais que começaram a se afloraram no mundo após a Primeira Guerra Mundial. Por isso, muitos dos métodos utilizados por Vargas eram visíveis em outros países, como, por exemplo, a criação de um departamento de propaganda do Estado na Alemanha, a criação de colégios internos preocupados com a formação moral, cívica e física dos alunos em Portugal, a padronização de livros didáticos na Itália e outras características.

Em 1938 foi criada a Comissão Nacional do Livro Didático (CNLD), órgão que objetivou regular e fiscalizar todos os livros didáticos em circulação no país. Foram criadas comissões e secretarias que trabalharam na regulamentação dos livros. Muitos livros não foram avaliados devido à grande demanda das editoras, mas mesmo assim foram utilizados dentro das salas de aula. Apesar disso, a CNLD exerceu forte 
influência na elaboração dos livros servindo, também, como modelo de avaliação para os próximos governos.

Para guiar nossa pesquisa fizemos o seguinte questionamento: qual a repercussão da CNLD dentro dos livros didáticos. E para responder a pergunta, dividimos o texto em duas partes: a primeira sobre a Comissão e a segunda sobre um livro didático oficial da época (História do Brasil de João Pereira Vitória, de 1946).

\section{A Comissão Nacional Do Livro Didático}

O ministro do Ministério Educação e Saúde, Gustavo Capanema, durante o Estado Novo brasileiro, sugeriu a Getúlio Vargas a criação de decreto-lei para fiscalizar a elaboração dos livros didático. A comissão foi criada em 1938 e "estabelecia que, a partir de $1^{\circ}$ de janeiro de 1940, nenhum livro didático poderia ser adotado no ensino das escolas préprimárias, primárias, normais, profissionais, e secundárias no país sem a autorização prévia do Ministério da Educação e Saúde" (FERREIRA, 2008: 38). Essa ação demonstra a preocupação do governo em controlar os conteúdos dos materiais que circulavam dentro das escolas.

No Estado Novo brasileiro observamos uma obsessiva política de repressão a tudo que era compreendido enquanto crítica ao Estado. Conforme afirmou Ferreira: "A centralização das políticas de controle deveria padronizar a literatura didática no país e evitar eventuais abusos decorrentes de iniciativa isolada estabelecidas por alguns estados da federação" (FERREIRA, 2008: 37). E a melhor forma de reprimir um le- 
vante seria a repressão sem violência, feita através da indústria cultural. De acordo com De Luca:

O regime não apenas interferiu de forma incisiva no campo educacional, mas levou a cabo, desde a subida de Vargas ao poder, um processo de centralização e expansão da máquina burocrática que, aliado a um ambicioso projeto no âmbito da cultura, alterou as relações entre intelectualidade e Estado (DE LUCA, 2009: 168).

Como afirmou a autora, a proposta de expansão da política do Estado Novo brasileira tinha como um dos seus pilares o ensino. A burocracia estava assentada em intelectuais que contribuíram nas mais diversas áreas. Só no Ministério da Educação e Saúde haviam nomes como o de "Carlos Drummond de Andrade, Mário de Andrade, Cândido Portinari, Manuel Bandeira, Heitor Villa-Lobos, Cecília Meireles, Lúcio Costa, Vinícius de Morais, Afonso Arinos de Melo Franco e Rodrigo Melo Franco de Andrade" (FERREIRA, 2008: 47).

A criação da Comissão Nacional do Livro Didático não pode ser estudada como um ato isolado nas reformas do governo e principalmente educacionais. Desde o primeiro governo varguista, em 1930, até o fim do Estado Novo, 1945, foram aprovadas diversas legislações referentes à educação. Destacamos a grande Reforma Francisco Campos, em 1931, que estabeleceu novas diretrizes de base para o sistema educacional brasileiro e a lei Orgânica do Ensino Secundário de 1942 (a mesma lei que obrigou a pausa da CNLD naquele ano). 
Também não podemos olhar o livro didático apenas como um instrumento ideológico. Ele é, como afirmou De Luca, um poliedro de múltiplas facetas. Suas faces, revelam aspectos pedagógicos, políticos e econômicos. E no Estado Novo brasileiro, o aspecto mercadológico se acentuou consideravelmente. Vejamos:

De fato, inaugurou-se um outro patamar de intervenção, se o Poder Executivo era o principal responsável pelo negócio, comprando e, indiretamente, influenciando decisões mercadológicas dos editores, ou pelo menos de parte deles, no novo regime o Estado passou a ser o incentivador, o organizador, o controlador e um comprador importante, o que redundou em forte dependência do setor editorial-didático (DE LUCA, 2009: 166).

No entanto, para o Estado as maiores contribuições foram no âmbito da política, porque o livro didático, em especial o de história, serviu para dar homogeneidade e coerência a uma história circunscrita em conflitos e contradições.

O julgamento dos livros por parte dos membros da CNLD eram feitos a partir do proposto pela Lei 1006 de 30 de dezembro de 1938 . Vejamos os parágrafos do Art.20 e do Art.21:

Art. 20. Não poderá ser autorizado o uso do livro didático:

a) Que atente, de qualquer forma, contra a unidade, a independência ou honra nacional;

b) Que contenha, de modo explícito ou implícito, pregação ideológica ou indicação da violência contra o regime político adotado pela Nação;

c) Que envolva qualquer ofensa ao chefe da Nação, ou às autoridades constituídas, ao Exército, à Marinha, ou às demais instituições nacionais; 
d) Que despreze ou escureça as tradições nacionais, ou tente deslustrar figuras dos que se bateram ou se sacrificaram pela pátria;

e) Que encerre qualquer afirmação ou sugestão, que induza o pessimismo quanto ao poder e ao destino da raça brasileira;

f) Que inspire o sentimento de superioridade ou inferioridade do homem de uma região do país com relação ao das demais regiões;

g) Que incite ódio contra raças e nações estrangeiras;

h) Que desperte ou alimente a oposição e a luta entre as classes sociais;

i) Que procure negar ou destruir o sentimento religioso ou envolva combate a qualquer confissão religiosa;

j) Que atente contra a família, ou pregue ou insinue contra a indissolubilidade dos vínculos conjugais;

k) Que inspire o desamor a virtude, induza o sentimento da inutilidade ou desnecessidade do esforço individual, ou combata as legítimas prerrogativas da personalidade humana.

Art. 21. Será ainda negada autorização de uso ao livro didático;

a) Que esteja escrito em linguagem defeituosa, quer pela incorreção gramatical quer pelo inconveniente ou abusivo emprego de termo ou expressões regionais ou da gíria, quer pela obscuridade do estilo;

b) Que apresente o assunto com erros de natureza científica ou técnica;

c) Que esteja redigido de maneira inadequada, pela violação dos preceitos fundamentais da pedagogia ou pela inobservância das normas didáticas oficialmente adotadas, ou que esteja impresso em desacordo com os preceitos essenciais da higiene da visão;

d) Que não traga por extenso o nome do autor ou dos autores;

e) Que não contenha a declaração do preço de venda, o qual não poderá ser excessivo em face do seu custo.

No Artigo 20 vemos a preocupação do governo com as questões políticas. Enquanto que no Artigo 21 observamos a preocupação com a aspecto pedagógico do livro. Assim, podemos enxergar uma moeda de duas faces: se por um lado há um objetivo centralizador, por outro há um intuito educacional. Podemos ver tênues divisórias nas políticas dos 
livros didáticos: centralizações que fazem censura, mas que ao mesmo tempo permitem liberdade. Ou seja, os livros que eram reprovados ficavam proibidos de serem usados nas escolas. E os professores tinham a liberdade de selecionar os materiais conforme uma lista fornecida pelo governo. No entanto, é inegável a preocupação maior do Estado com as narrativas em relação às questões políticas pois os Parágrafos do Artigo 20 são mais numerosos do que o Artigo 21.

No artigo 21 detectamos uma visão social de mundo, ou seja, ideias que não necessariamente pretendem exercer dominação. A preocupação com livros, "redigido de maneira inadequada, pela violação dos preceitos fundamentais da pedagogia", pressupões uma visão utópica, que pretende romper com o analfabetismo, levando a leitura e a escrita para os rincões do Brasil. Sendo assim, no Estado Novo há, além de políticas de centralização, propostas de rompimento com a tradição do analfabetismo.

A CNLD, como já dissemos, tinha o objetivo de padronizar os livros didáticos. Todavia, até o final do Estado Novo brasileiro, ela nunca conseguiu funcionar com plenitude. O número alto de compêndios enviados a Comissão ligada aos poucos membros encarregados de analisar os livros fez com que muitas obras fossem para a escola sem a autorização do Ministério. Também houve interrupção no seu funcionamento, no ano de 1942, por causa da mudança na lei Orgânica de Ensino. Até o final de 1941 tinham sido examinados 340 livros e restavam 1646. Infelizmente não sabemos com precisão todos os livros que foram aprovados e reprovados pela CNLD. Até onde se sabe os relatórios nunca fo- 
ram divulgados (FERREIRA, 2008: 116.), mas os livros aprovados eram portadores de um carimbo do "Ministério da Educação e Saúde", fator que possibilita identifica-los nos dias atuais.

A CNLD foi a primeira tentativa de padronização, como já referido, e funcionou até o ano de 1969, após a instauração da ditadura militar.

\section{O livro didático de João Pareira Vitória}

O livro didático de História do Brasil de João Pereira Vitória foi selecionado para este trabalho porque ele era um material autorizado pelo governo. Dessa forma, foi avaliado, aprovado e teve repercussão nas escolas. O livro possui um recorte temporal dá Independência até os dias atuais da época, isto é, 1946. Sua escrita está inserida naquelas tradições historicistas de narrativa, pautadas em grandes líderes, grandes fatos históricos e grandes acontecimentos.

Curiosamente neste livro há um capitulo específico sobre a história do governo Vargas, mas a tradição historiográfica da História do passado recente só vingou nas produções acadêmicas a partir dos anos de 1970, apesar de Marc Bloch já defendê-la nos anos de 1930. Por isso, é de se perguntar o porquê da existência desse capítulo no livro. Mas veremos adiante que não se trata de um método inovador de se ensinar história, mas sim de um recurso para se elogiar o Governo Vargas.

A nossa análise observou a exclusão de diversos atores sociais dos processos históricos no livro didático. Na grande maioria e esmagadora das vezes, as mudanças que são feitas no país são retratadas por 
meio de um indivíduo que assume a ação, ou então, o Estado personifica um indivíduo que realiza o acontecido. Vejamos alguns exemplos: Primeiramente o autor ao se referir às campanhas de opinião para as eleições de 1946, dá ênfase ao então Presidente Vargas como zeloso aos processos eleitorais, conforme segue: “Em princípios de 1945, após renhidas campanhas de opinião, o dr Getúlio Vargas marcou o dia 2 de Dezembro desse ano, para as eleições gerais" (Vitória, 1946: 240). Observemos, que a atitude do então Presidente de marcar as eleições não ocorreu por causa das pressões da oposição, mas pela própria vontade do presidente.

Na mesma direção, João Pereira Vitória, continuou construindo uma representação positiva do então presidente ao relar que "a partir deste momento, pode, o dr Getúlio Vargas, desfazer-se de certas influências políticas, que lhe dificultavam a governança e tratou de ir preparando o país para a nova ordem legal" (Vitória, 1946: 230). Ou seja, os problemas pelos quais passava o país foram consequência das influências das ideologias comunista e socialista, conforme bradava a imprensa da época. E somente a partir do golpe do Estado Novo e da implantação de uma nova ordem, o país superaria os desafios enfrentados. Vargas novamente é representado como um salvador nacional, um herói que tem as soluções para o país.

Ainda com a perspectiva personalista da política brasileira, $o$ autor afirma que "Afrânio Peixoto, figura das de maior projeção no atual momento brasileiro, erudito, em todos os ramos do saber, tem aplicado os ricos dons de sua privilegiada inteligência" (Vitória, 1946: 242). Nes- 
ta afirmação percebe-se uma História Biográfica e Estatal, ou seja, características de influência historicista. Dessa forma a História produzida por João Pereira Vitória se centra no estudo da História através de sua manifestação individual e constrói um discurso historiográfico que prioriza as ações dos "homens" de destaque na esfera da política nacional. Nesse sentido, o autor foi fiel a proposta historiográfica historicista, que José Carlos Reis definiu como uma História que se manifestava de forma individual (REIS, 1999: 12).

A afirmação de que manifestação da história ocorre somente através de pessoas vem atrelada a ideia de que não são quaisquer pessoas mas aqueles que possuem qualidades. Tais qualidade seriam expressas por suas ações de destaque dentro da esfera do político e, portanto, representariam as causas dos fenômenos históricos. Ao historiador caberia assim, "recuperar os eventos, suas interconexões e suas tendências através da documentação e fazer-lhes a narrativa" (REIS, 1999: 12).

Construímos uma tabela para ter melhor dimensão da quantificação das ideias com maior frequência no capítulo que trata do Governo Vargas (Tabela 1). Observemos que os elementos que predominam no texto são o desenvolvimento econômico e o progresso intelectual. Segundo o livro, "nunca se cultivou tanto a inteligência. Multiplicam-se as escolhas primárias, secundárias e superiores. As livrarias estão repletas de novas obras de grande valor. A imprensa e o rádio são os maiores propulsores da divulgação do pensamento em todas as suas manifestações" (Vitória, 1946: 228). 
Em outro trecho que nos chama atenção o autor homenageia o historiador o Pedro Calmon: "o elegante historiador Pedro Calmon, parece não ter outro ideal senão o de alimentar a chama patriótica, através de magníficas obras em que a elegância do estilo se alia à seriedade dos assuntos" (Vitória, 1946: 243).

\section{Tabela 1}

\begin{tabular}{|c|c|c|c|c|c|c|}
\hline \multicolumn{7}{|c|}{ Capitulo de passado recente do livro de História do Brasil } \\
\hline $\begin{array}{l}\text { Unidade de } \\
\text { referência }\end{array}$ & $\begin{array}{l}\text { Dispu- } \\
\text { tas } \\
\text { políti- } \\
\text { cas na } \\
\text { década } \\
\text { de } \\
1930\end{array}$ & $\begin{array}{l}\text { Golpe } \\
\text { para } \\
\text { afastar } \\
\text { a ame- } \\
\text { aça } \\
\text { comu- } \\
\text { nista e } \\
\text { integra- } \\
\text { lista em } \\
1937 \\
\end{array}$ & $\begin{array}{l}\text { Manu- } \\
\text { tenção } \\
\text { da } \\
\text { integri- } \\
\text { dade } \\
\text { após a } \\
\text { década } \\
\text { de } \\
1930\end{array}$ & $\begin{array}{l}\text { Prestí- } \\
\text { gio } \\
\text { inter- } \\
\text { nacio- } \\
\text { nal }\end{array}$ & $\begin{array}{l}\text { Desen- } \\
\text { volvi- } \\
\text { mento } \\
\text { econô- } \\
\text { mico }\end{array}$ & $\begin{array}{l}\text { Progres- } \\
\text { so inte- } \\
\text { lectual }\end{array}$ \\
\hline 226 & $\mathrm{X}$ & $\mathrm{X}$ & & & & \\
\hline 227 & & & $\mathrm{X}$ & $\mathrm{X}$ & $\mathrm{X}$ & \\
\hline 228 & $\mathrm{X}$ & & & & & $\mathrm{X}$ \\
\hline 229 & $X$ & & & & & \\
\hline 230 & & & $\mathrm{X}$ & & & $\mathrm{X}$ \\
\hline 231 & & $\mathrm{X}$ & & & & \\
\hline 232 & & $X$ & $\mathrm{X}$ & & & \\
\hline 233 & & & & & & \\
\hline 234 & & & & & & \\
\hline 235 & & & & $\mathrm{X}$ & & \\
\hline 236 & & & & $\bar{X}$ & & \\
\hline 237 & & & & & & \\
\hline 238 & & & & & $X$ & \\
\hline 239 & & & & & $\mathrm{X}$ & $\mathrm{X}$ \\
\hline 240 & & & & & $X$ & \\
\hline 241 & & & & & $\mathrm{X}$ & \\
\hline 242 & & & & & & $X$ \\
\hline 243 & & & & & & $X$ \\
\hline 244 & & & & & & $X$ \\
\hline Total & 3 & 3 & 3 & 3 & 5 & 6 \\
\hline
\end{tabular}


A partir da tabela apresentada podemos perceber que entre os eventos mais citados na narrativa didática de João Pereira Vitória localizamos fatos centrados no relato dos progressos intelectuais vivenciados pela nação durante o governo de Getúlio Vargas. Isso evoca ao líder do país um papel ilustrado de governante esclarecido que presou pelo desenvolvimento da nação. Esse desenvolvimento, especificamente o econômico, é o segundo tema mais abordado no capítulo sobre aos tempos contemporâneos, mas a abordagem do texto é feita como um elogio ao próprio Vargas.

A visão de História que perpassa essa obra é a mesma que dirigiu ainda nas décadas seguintes a produção dos livros didáticos de História e contribuiu para a manutenção dos estereótipos e representações dos papéis sociais aprendidos nas escolas e nas salas de aula de História.

\section{Considerações Finais}

Pudemos observar nesse artigo a criação da CNLD como um aparato de controle estatal dos mecanismos educacionais. Vimos que os manuais oficiais, a exemplo do manual didático de João Pereira Vitória, repercutem no seu interior um elogio ao Estado Brasileiro, omitindo conflitos, incongruências e desordens sociais.

O fato da CNLD proibir quaisquer tipos de críticas aos líderes de notório reconhecimento nacional converge com uma História historicista, que vê em seus governantes um dos principais motores da história. Por isso, a união da perspectiva de escrita da história em voga na época junto com as ideias nacionalistas e centralizadoras de Vargas tenderam a 
construir uma identidade nacional que não evidenciou a heterogeneidade do Brasil.

\section{Fontes}

A presente pesquisa possui como fonte principal o livro didático História do Brasil - $4^{\circ}$ Série de João Pereira Vitória. A obra conta a história brasileira, desde a independência até os dias atuais, na época 1945. O compendio encontra-se salvaguardado na Biblioteca Riograndense (Rio Grande - RS). Segundo o catálogo impresso na fonte, ela está de acordo com o programa oficial, seguindo a legislação da CNLD, do ano de 1942.

Legislação que regulamenta a Comissão Nacional do Livro Didático, sendo esta a Lei 1006 de 30 de dezembro de 1938. Disponível em: http://www2.camara.leg.br/legin/fed/declei/1930-1939/decreto-lei1006-30-dezembro-1938-350741-publicacaooriginal-1-pe.html.

Último Acesso: 02/05/2014.

\section{Bibliografia}

ABUD, Katia Maria. Formação da Alma e do Caráter Nacional: Ensino de História na Era Vargas. Rev. Bras. Hist. [online]. 1998, Vol. 18, n. 36, pp. 103-114.

ADÃO, Áurea; REMÉDIO, Maria José. A narratividade educativa na $1^{\text {a }}$ fase da governação de Oliveira Salazar. A voz das mulheres na Assembleia Nacional portuguesa (1935-1945). IN: Revista Lusófona de Educação. 5, 85-109, 2005. 
AMARAL, Azevedo. A Nação e o Estado. In: O Estado Autoritário e a Realidade Nacional. Versão para ebook, 2002.

ALVES, Francisco das Neves \& MATOS, Júlia Silveira. Teoria e historiografia no Rio Grande do Sul: ensaios históricos. Rio Grande: Universidade Federal do Rio Grande, 2011.

BITENCOURT, Circe Maria F. Ensino de História - Fundamentos e Métodos. Cortez, 2008.

BOMENY, Helena M. B. Três decretos e um ministério: a propósito da educação no Estado Novo. In: Repensando o Estado Novo. Rio de Janeiro: Ed. Fundação Getúlio Vargas, 1999.

BOMENY, Helena. Constelação Capanema: intelectuais e política. Rio de Janeiro: Ed. Fundação Getúlio Vargas; Bragança Paulista (SP). Ed. Universidade de São Francisco, 2001.

CARVALHO, Romulo de. História do ensino em Portugal: desde a fundação da nacionalidade até o fim do regime de Salazar-Caetano. 3 ed. Lisboa: Fundacão Calouste Gulbenkian, 2001.

CHOPPIN, Alain. História dos Livros e das Edições Didáticas. Disponível em: http://www.scielo.br/pdf/ep/v30n3/a12v30n3.pdf. Acessado em 21/04/2012 às $19 \mathrm{~h}$.

DE LUCA, Tânia Regina. Livros didáticos e Estado: explorando possibilidades interpretativas. IN: Histórica na escola. Editora FGV. 2009.

ENCONTRO REGINAL DE HISTÓRIA: PODER, VIOLÊNCIA E EXCLUSÃO. 19., 2008. São Paulo. Anais... São Paulo: OS PROCESSOS DE AVALIAÇÃO DE LIVROS DIDÁTICOS NA COMISSÃO NACIONAL DO LIVRO DIDÁTICO, 2008. CD-ROM.

FERREIRA, Rita de Cássio Cunha. A comissão nacional do livro didático durante o estado novo (1937 - 1945). Assis 2008.

FILGUEIRAS, Juliana Miranda. Os processos de avaliação de livros didáticos na Comissão Nacional do Livro Didático, 2008. In: ENCONTRO REGINAL DE HISTÓRIA: PODER, VIOLÊNCIA E EXCLUSÃO. 19., 2008. São Paulo. Anais.. São Paulo:. CD-ROM. 
FONSECA, Selva Guimarães. Caminhos Da História Ensinada. 10. ed. Papirus Editora, 1993.

FONSECA, Selva Guimarães. Didática E Prática de Ensino de História. 7. ed. Papirus Editora, 2008.

JUNIOR, Antônio Gasparetto. Países do Eixo. Disponível em: <www.infoescola.com/segunda-guerra/paises-do-eixo>. Data de acesso 24/2013.

GONÇALVES, Andréa Lisly. História e Gênero. Belo Horizonte: Autêntica, 2006.

MIGUEL, Maria Elisabeth Blanck e CORRÊA. Rosa Lidia Teixeira. A educação escolar em perspectiva histórica. Campinas, SP: Autores Associados, 2005.

MONTEIRO, Ana Maria; GASPARELLO, Arlette Medeiro; MAGALHÃES, Marcelo de Souza. Ensino de História - Sujeitos, saberes e práticas. Rio de Janeiro: MAUAD X, 2007.

MORAES, Roque. Mergulhos discursivos, análise textual qualitativa entendida como processo integrado de aprender, comunicar e interferir em discursos. IN: Metodologia emergente de pesquisa em educação ambiental. $2^{\circ}$ ed. Ijuí RS: Editora Unijuí, 2007

ORTIZ, Renato. Cultura brasileira e identidade nacional. São Paulo: Editora Brasiliense, 2006.

REIS, José Carlos. As identidades do Brasil de Calmon a Bomfim. Rio de Janeiro: Editora FGV, 2006.

REIS, José Carlos. Escola dos Annales: A inovação em História. São Paulo. Paz e Terra, 2000.

REIS, José Carlos. Nouvelle Histoire e tempo histórico: a contribuição de Febvre, Bloch e Braudel. São Paulo. Editora Ática, 1994. 